\title{
Maternal and perinatal outcome in rupture of unscarred uterus: a case series
}

\author{
Ancy M. Kurian, Indrani Roy*, Neelotparna Saikia, Kerlin Mihsill
}

Department of Obstetrics and Gynecology, Nazareth Hospital, Shillong, Meghalaya, India

Received: 25 June 2021

Revised: 20 July 2021

Accepted: 21 July 2021

\section{*Correspondence:}

Dr. Indrani Roy,

E-mail: indraniroydeb@gmail.com

Copyright: ( ) the author(s), publisher and licensee Medip Academy. This is an open-access article distributed under the terms of the Creative Commons Attribution Non-Commercial License, which permits unrestricted non-commercial use, distribution, and reproduction in any medium, provided the original work is properly cited.

\begin{abstract}
Uterine rupture is one of the main contributory factors of maternal morbidity and fetal mortality. The aim of this study was to study the maternal and perinatal outcome in rupture of unscarred uterus and to identify the etiology, risk factors, diagnosis and management in a tertiary care centre. This case series study was often cases of rupture of unscarred uterus conducted at the department of obstetrics and gynecology, Nazareth hospital, Shillong, Meghalaya from July 2018 to February 2021. During the study period there were 7840 deliveries and ten patients presented with rupture of unscarred uterus, the incidence being $0.127 \%$. The patients were referred from different primary health centres and all patients presented with history of trial of home delivery. All patients were multigravida and the highest parity was a patient with para 11 . The cases were between the gestational age of 39 to 41 weeks. Rupture was observed in the lower uterine segment in 5 patients, left lateral wall in 3 and right lateral wall in 2 patients. Five patients underwent hysterectomy, and 4 patients had repair of the rupture. There was one maternal death. Grand multipara and trial of home delivery were the most common identifiable risk factors along with obstructed labour. Identifying high risk women, prompt diagnosis, early referral from periphery and active management is the key factor to avoid adverse maternal and perinatal outcome.
\end{abstract}

Keywords: Uterine rupture, Home delivery, Grand multipara, Hysterectomy, Obstructed labour

\section{INTRODUCTION}

Uterine rupture is a life-threatening and catastrophic event in a woman's life. ${ }^{1}$ Primary rupture is defined as rupture in a previously intact or unscarred uterus, and secondary when it is associated with a pre-existing incision, injury, or anomaly of the myometrium. ${ }^{2}$ It may not only endanger the life of mother and fetus but also may even affect her future fertility status. ${ }^{3}$

In developed countries according to the data available, uterine rupture for women with previous caesarean delivery is around $1 \%$, whereas for women without previous caesarean delivery, based on one large report, it is extremely rare $(<1$ per 10,000$)$. Overall, the rates are below 1 per $1000 .{ }^{4}$ In a study done in Ethiopia the overall incidence of uterine rupture was 1 in $110 .^{5}$
An unscarred uterus may rupture later in gestation than a scarred uterus. ${ }^{6}$ The damage to the uterus may be beyond repair and hysterectomy may be the treatment modality.

A major factor in uterine rupture is obstructed labour, other factors include multiparity and particularly grand multiparity, the use of uterotonic drugs to induce or augment labour, placenta percreta, rarely intrauterine manipulations such as internal podalic version, breech extraction and high frequency of home deliveries with prolonged labour. ${ }^{3,7}$ Primary uterine rupture cases have a "greater maternal morbidity, greater mean blood loss, a higher rate of blood transfusion, and a higher frequency of peripartum hysterectomy" than rupture of a scarred uterus. $^{1}$ 
The occurrence of rupture uterus varies in different parts of the world with a significant reduction in frequency in the developed countries in recent times. Nevertheless, it is still a major public health problem in developing countries. $^{8}$

\section{CASE SERIES}

This is a case series study conducted at the department of obstetrics and gynecology, Nazareth hospital, Shillong, Meghalaya, India from July 2018 to February 2021. A total of 7840 deliveries and 10 unscarred ruptured uterus were recorded during the 32 months of study period. This gives an overall incidence of 1 uterine rupture for every 784 deliveries. In this review there were no primigravidae or preterm pregnancy.

Table 1: Demographic details.

\begin{tabular}{|ll|}
\hline Characteristic & Observation (n=10) \\
\hline Mean age (years) & 32.7 \\
\hline Mean gestational age (weeks) & 40.3 \\
\hline Parity N (\%) & \\
\hline$<5$ & $4(40)$ \\
\hline$\geq 5$ & $6(60)$ \\
\hline Referred cases N (\%) & $10(100)$ \\
\hline Tried home delivery & $10(100)$ \\
\hline Presentation & \\
\hline Cephalic & $9(90)$ \\
\hline Transverse & $1(10)$ \\
\hline
\end{tabular}

All the women in our study were referred from different peripheral health centers for further management and had history of poor antenatal check-ups. All the patients had history of trying home delivery before going to any medical facility.

Table 2: Complications $(\mathbf{n}=\mathbf{1 0})$.

\begin{tabular}{|ll|}
\hline Complications & $\mathbf{N}(\%)$ \\
\hline Blood transfussion & $9(90)$ \\
\hline Urinary incontinence & $3(30)$ \\
\hline Bladder injury & $1(10)$ \\
\hline Ureter injury & $1(10)$ \\
\hline Wound infection & $1(10)$ \\
\hline Sepsis & $1(10)$ \\
\hline Blood transfussion & $9(90)$ \\
\hline Urinary incontinence & $3(30)$ \\
\hline
\end{tabular}

The age of the women was in the range of 21 to 39 years with a mean of $32.7 \pm 5.6$ years. Among the cases five had more than one day delay to reach a medical facility after the onset of labour. All women were multipara and among them six were grand multiparae. Gestational age was between 39-41, the mean gestational age being $40.3 \pm 1.2$ weeks.

Nine women who were in labour presented with signs and symptoms of uterine rupture, while one woman came to emergency room gasping and succumbed to death in emergency room before any active intervention could be initiated. At admission two patients were in shock, four patients presented with bleeding per vagina, five had abdominal tenderness and in three patients fetal parts were palpable easily per abdomen.

Table 3: Fetal outcome $(n=10)$.

\begin{tabular}{|lc|}
\hline Fetal outcome & N $(\%)$ \\
\hline Intrauterine death & $7(70)$ \\
\hline Severe asphyxia & $3(30)$ \\
\hline Perinatal death & $1(10)$ \\
\hline
\end{tabular}

*Number does not correlate as same baby is involved in more than one outcome

The most common site of uterine rupture in five patients was in the lower uterine segment, other sites were left and right lateral wall for three and two patients respectively. The patient who had succumb to death in the emergency department underwent a post-mortem caesarean section which showed the rupture in the lower uterine segment. All cases underwent surgical intervention. Repair of rupture site was performed in four cases and hysterectomy was performed in the remaining five cases. The associated surgeries included bladder repair in one case and ureter repair in one case.

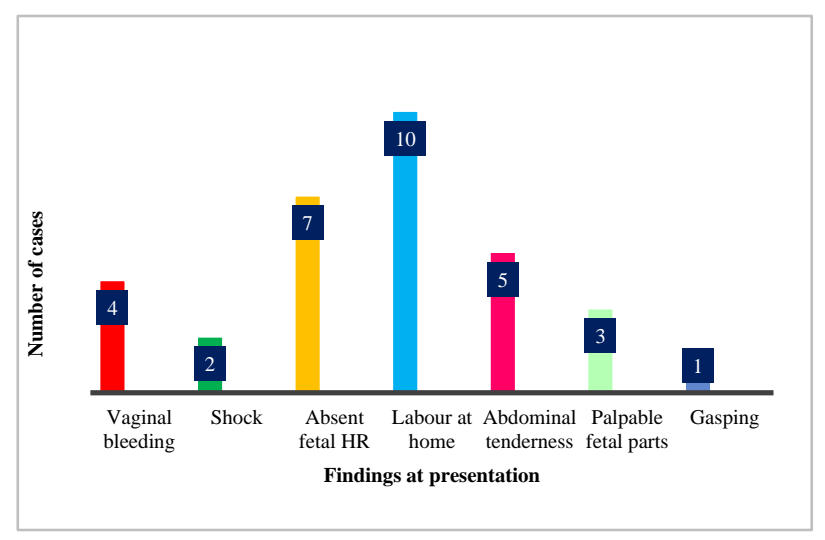

Figure 1: Signs, symptoms and examination findings at presentation.

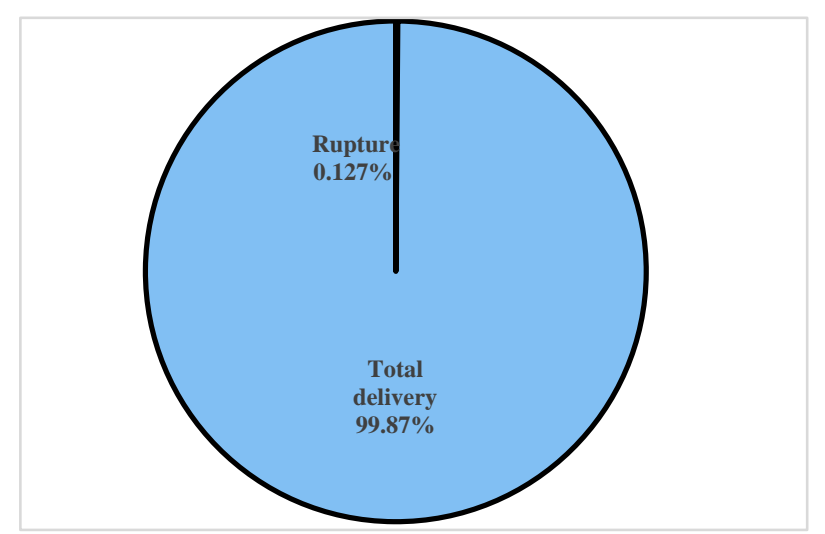

Figure 2: Incidence of unscarred uterine rupture. 
All patients received blood transfusion, and maximum of five units was transfused in one patient. Four patients received inj. Iron sucrose in additional to blood transfusion. Five patients required Intensive Care Unit admission postoperatively. The hospital stays ranged between 7 to 26 days in all nine patients. Seven patients presented with intrauterine fetal demise while three babies were born depressed with low APGAR scores and one resulting in perinatal death.

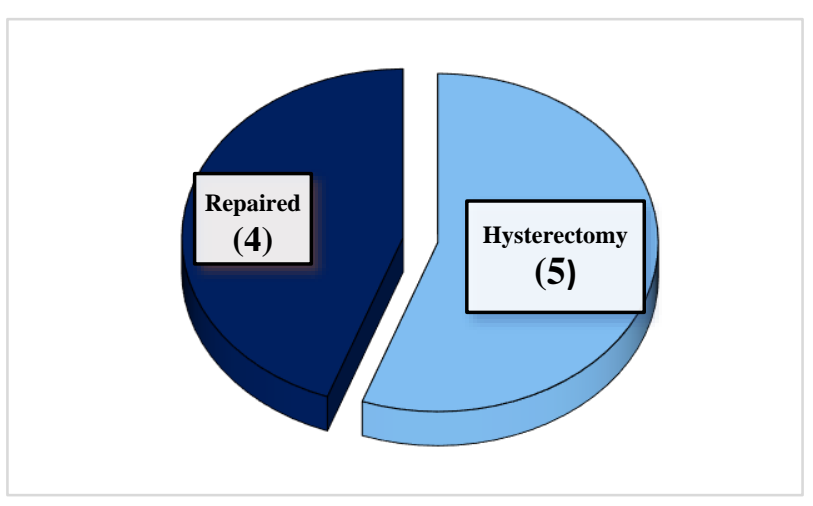

Figure 3: Surgical management $(n=9)$.

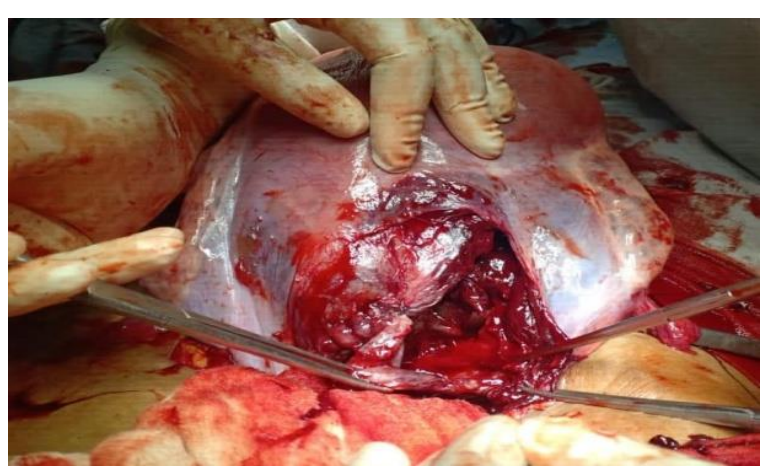

Figure 4: Intra-operative image demonstrating the rupture in the lower segment.

\section{DISCUSSION}

The incidence of uterine rupture in the present study was $0.127 \%$ which is higher than that in a study done by Vernekar et al which was $0.057 \% .^{3}$ A study from a developed country gave prevalence of $0.006 \%$ for uterine rupture in unscarred uterus. ${ }^{4}$ In women without any history of caesarean delivery or any other gynaecological surgery uterine rupture is highly unusual. ${ }^{4}$ One report says that women over 30 years of age have been reported to have two to three times the risk of uterine rupture than women less than 30 years. $^{6}$ Uterine rupture is more frequent in developing and underdeveloped countries which is one of the causes leading to maternal and perinatal mortality. ${ }^{4}$ Similar to the study by Nurullah Peker et al in which more than half $(56.7 \%)$ of cases under went hysterectomy, the present study also had more than half $(55.5 \%)$ cases who underwent hysterectomy. ${ }^{8,9}$ In most of the patient's rupture occurred in the lower uterine segment and hysterectomy was performed in most of them.

In the literature, the risk factors for unscarred uterine rupture are: high parity, use of uterotonic drugs, advanced maternal age, dystocia, macrosomia and possibly short inter-pregnancy intervals. ${ }^{7-11}$ High incidence in this study is a reflection of prolonged trial of labour at home, delay in referral of the cases from peripheral health centers and further delay due to poor transport facilities in the rural area. A high index of suspicion should be held when labor involves unbooked patients, grand multiparity, or previously scarred uterus.

In this study uterine rupture was diagnosed correctly only in three of the cases by the referring health institution. To reduce the prevalence of uterine rupture, health education and awareness of availability of health care services should be given to the people. The need of the hour is proper training of the local health care workers in making early identification of high risk factors in women, encouraging institutional deliveries particularly, in women of multiparity and grand multiparity, with provision for easy and quick accessibility to obstetric services including caesarean delivery for obstructed labour.

\section{CONCLUSION}

Uterine rupture still remains a major obstetric challenge, more in the rural areas of the country. The major obstacles are ignorance on the part of the women, and inattention to medical advice. More number of attempted home deliveries, abdominal massage practices, coupled with self-denials, leads to unnecessary delay in obtaining a medical help. Identification of women at risk, monitoring of labour progression by partogram, avoiding prolonged labour, prompt and early referral to a higher centre are key factors in avoiding such adverse outcomes. Therefore, the need for rigorous public enlightenment and encouragement of institutional deliveries will go a long way to ensure better maternal and perinatal outcome.

\section{Funding: No funding sources \\ Conflict of interest: None declared \\ Ethical approval: Not required}

\section{REFERENCES}

1. Halassy SD, Eastwood J, Prezzato J. Uterine rupture in a gravid unscarred uterus: A case report. Case Rep Women's Health. 2019;24:e00154.

2. Cunningham FG, Leveno kenneth J, Bloom SL, Dashe JS, Hoffman BL, Casey BM, et al. Williams Obstetrics. 25th ed. New York: McGraw-Hill; 2018.

3. Vernekar M, Rajib R. Unscarred uterine rupture: A retrospective analysis. J Obstet Gynecol India. 2016; 66(1):51-4.

4. Hofmeyr GJ, Say L, Gülmezoglu AM. WHO systematic review of maternal mortality and 
morbidity: The prevalence of uterine rupture. Int $\mathrm{J}$ Obstet Gynaecol. 2005;112(9):1221-8.

5. Ahmed DM, Mengistu TS, Endalamaw AG. Incidence and factors associated with outcomes of uterine rupture among women delivered at Felegehiwot referral hospital, Bahir Dar, Ethiopia: Cross sectional study. BMC. 2018;18(1):1-12.

6. You S, Chang Y, Yen C. Taiwanese journal of obstetrics \& gynecology rupture of the scarred and unscarred gravid uterus : outcomes and risk factors analysis. Taiwan J Obstet Gynecol. 2018;57(2):24854.

7. Posthumus L, Donker ME. Uterine rupture in a primigravid patient, an uncommon but severe obstetrical event: A case report. J Med Case Rep. 2017;11(1):9-12.

8. Gupta A, Nanda S. Uterine rupture in pregnancy: A five-year study. Arch Gynecol Obstet. 2011;283(3): 437-41.
9. Peker N, Aydin E, Evsen MS, Hançer FN, Bademkiran $\mathrm{MH}$, Ege $\mathrm{S}$, et al. Unscarred uterine rupture and subsequent pregnancy outcome-a tertiary centre experience. Ginekol Pol. 2020;91(2):95-9.

10. Wielgos M, Bomba-Opon D, Breborowicz GH, Czajkowski K, Debski R, Leszczynska-Gorzelak B, et al. Recommendations of the Polish society of gynecologists and obstetricians regarding caesarean sections. Ginekol Pol. 2018;89(11):644-57.

11. Khoiwal K, Agarwal A, Gaurav A, Yadav P, Chaturvedi J. Why women still die of childbirth in the 21st century: A case report on uterine rupture in unscarred uterus. J Med Evid. 2021;2(1):40.

Cite this article as: Kurian AM, Roy I, Saikia N, Mihsill K. Maternal and perinatal outcome in rupture of unscarred uterus: a case series. Int J Reprod Contracept Obstet Gynecol 2021;10:3204-7. 